\title{
Seguindo as pegadas de Sherlock Holmes: uma proposta de atividade investigativa utilizando novas tecnologias
}

\author{
Paulo Victor Santos Souza*, Fernando dos Santos Neto**, Marta Maximo-Pereira***
}

\section{Resumo}

Repensar o papel das novas tecnologias da informação e comunicação (TIC) no ensino e refletir sobre a forma de se trabalhar assuntos da Cinemática no Ensino Médio são duas questões que estão colocadas para a pesquisa em Ensino de Física. Neste trabalho é apresentada uma proposta de atividade investigativa experimental que envolve o uso das TIC na elaboração de um modelo para o caminhar de uma pessoa. A questão que dá ensejo à atividade se baseia em um fragmento do livro "Um estudo em vermelho", no qual o famoso personagem Sherlock Holmes fez sua estreia na literatura. Os dados do experimento são obtidos e tratados mediante o uso dos softwares livres Tracker e LibreOffice/Calc. Este artigo busca mostrar que as TIC podem fornecer uma importante contribuição à aprendizagem de conhecimentos e de práticas que caracterizam o fazer científico, desde que sejam utilizadas no contexto de atividades elaboradas para tais finalidades, sendo o ensino por investigação uma abordagem didática apropriada para isso.

Palavras-chave: Ensino de Física; Ensino por investigação; TIC; Cinemática.

- Doutor em Física pela Universidade Federal Fluminense. Professor do Instituto Federal de Educação, Ciência e Tecnologia do Rio de Janeiro campus Volta Redonda, Brasil. E-mail: paulo.victor@ifrj.edu.br

* Mestre em Ensino de Física pela Universidade Federal Fluminense campus Volta Redonda. Professor do Colégio Interativo, Volta Redonda - RJ, Brasil. E-mail: fernando_zell@hotmail.com

*** Doutora em Ciências pelo Programa de Pós-Graduação Interunidades em Ensino de Ciências (modalidade Ensino de Física) da Universidade de São Paulo. Professora do Centro Federal de Educação Tecnológica Celso Suckow da Fonseca campus Nova Iguaçu, Brasil. E-mail: martamaximo@yahoo.com 


\section{Introdução}

As pesquisas em Ensino de Ciências e, em especial, em Ensino de Física, desde a década de 60 do século XX (NARDI; ALMEIDA, 2004), já apontavam para a necessidade de que as práticas na sala de aula dessa disciplina fossem transformadas (BARROS, 2002; FOUREZ, 2003), a fim de aumentar o interesse dos estudantes e ampliar sua compreensão sobre os fenômenos e conceitos físicos. Mesmo que essa preocupação não seja recente na área, ela ainda é um pressuposto para grande parte das propostas didáticas elaboradas. Isso ocorre porque o caminho entre a pesquisa e as salas de aula, a teoria e a prática, a proposição e a ação concreta não é linear nem trivial (PENA, 2004), sendo permeado por questões que envolvem a formação inicial e continuada de professores, condições concretas de trabalho e estudo, políticas educacionais, entre outros fatores.

Neste trabalho, defendemos que os alunos realizem pequenas investigações nas aulas de Física, as quais são entendidas como "[...] processos por meio dos quais novos conhecimentos são construídos apoiando-se em resultados teóricos, dados empíricos, análise e confronto de perspectivas" (SOLINO; FERRAZ; SASSERON, 2015, p. 2). Tais investigações visam possibilitar a formulação de hipóteses e de modelos explicativos, com base na elaboração de conhecimento científico, e desmistificar a visão popular sobre a ciência - frequentemente tida como inatingível, complexa e distante da realidade das pessoas (SENRA; BRAGA, 2014; VITAL; GUERRA, 2014). Propomos também a utilização de ferramentas tecnológicas como possibilidade para auxiliar na realização dessas atividades e engajar os estudantes em processos formais de aprendizagem em sala de aula (PIRES; VEIT, 2006).

Para a aproximação entre investigação escolar e os recursos fornecidos pelas tecnologias da informação e comunicação (TIC), consideramos, como abordagem didática, o ensino por investigação (SASSERON, 2015). Assim, o objetivo deste artigo é apresentar uma proposta de atividade investigativa (AZEVEDO, 2004; SOUSA et $a l, 2015$; FRAIHA et al, 2018) que envolve a modelagem de um fenômeno inserido em um contexto de investigação e mistério, ainda que relativamente simples: o caminhar de uma pessoa. Para tanto, o problema que dá ensejo à atividade investigativa foi elaborado a partir de um fragmento do livro "Um estudo em vermelho" (DOYLE, 2015), no qual a personagem de Sherlock Holmes, detetive famoso por desvendar crimes e enigmas, fez sua primeira aparição. Para a solução do proble- 
ma, é proposta a realização de um experimento, que consiste em filmar uma pessoa em duas situações distintas: enquanto caminha um dado trecho em linha reta e enquanto corre o mesmo trecho. Os softwares livres Tracker e LibreOffice / Calc (DE JESUS; SASAKI, 2014; DE JESUS; SASAKI, 2016) são usados para a coleta e a análise dos dados. A experimentação de caráter investigativo e as TIC inserem-se como possibilidades para a resolução do problema colocado, sendo sempre problematizadas junto aos estudantes.

A atividade proposta envolve o conceito de velocidade, a modelagem matemática de fenômenos, a construção de tabelas, a confecção e análise de gráficos, entre outros assuntos geralmente associados ao estudo da Cinemática. Sobre a pertinência do ensino dessa temática no contexto do Ensino Médio, a literatura da área de Ensino de Ciências recorrentemente a aponta como um tema controverso.

Alguns autores defendem a exclusão da Cinemática dos currículos (MENEZES, 1994; MOREIRA, 2018), com base em alguns argumentos, como, por exemplo: a excessiva matematização envolvida na forma como essa parte da Física é tradicionalmente abordada pelos professores e pelos livros didáticos, o que acaba gerando desinteresse por parte dos alunos; o grande tempo destinado a esse assunto na maioria dos currículos em ação nas escolas, o que faz com que outras temáticas relevantes não sejam discutidas; a necessidade de mais espaço em sala de aula para a abordagem de temas de Física Moderna e Contemporânea. Outros autores defendem a presença da Cinemática nas aulas, com base no fato de que historicamente a Física se inicia com os estudos sobre o movimento (GASPAR, 1994) e na função "propedêutica" desse assunto, que atuaria como requisito para o estudo de assuntos posteriores de Física e de outras Ciências (SOUZA; DONANGELO, 2012).

No entanto, esses dois grupos de posicionamento distintos têm acordo em que a crítica talvez mais fundamental não seja à Cinemática em si, mas sim à maneira como ela é apresentada na maioria dos casos pelos professores e pelo livro didático. Buse (2014) mapeia alguns dos problemas que historicamente têm caracterizado a forma como a Cinemática é abordada em sala de aula:

"a dificuldade por parte do aluno da visualização concreta do movimento, reduzindo seu conhecimento a algo abstrato e infrutífero; o distanciamento da realidade vivida com aquilo que é apresentado em sala de aula; a abordagem excessiva na resolução de exercícios que induzem o aluno a formar uma imagem errônea da cinemática, limitando esta à aplicação de várias fórmulas na resolução de problemas repetitivos e artificiais; e o tempo muitas vezes despendido pelo professor de física na retomada 
de definições e operações matemáticas necessárias para a resolução dos exercícios de cinemática em detrimento de outros conteúdos que compõem o currículo da física escolar [...]" (BUSE, 2014, p. 29).

Diante desse panorama, Buse (2014) propõe que uma solução possível seja não descartar diretamente a Cinemática, mas sim repensar as formas de sua inserção no Ensino Médio. Algumas propostas já têm sido feitas nessa direção (LIMA; SOARES, 2010; SOUZA; DONANGELO, 2012; BELMONT; MAXIMO-PEREIRA; LEMOS, 2016). O presente trabalho se alinha a essa tendência, qual seja, a de repensar o papel e a forma de se trabalhar a Cinemática na Educação Básica e se coloca como uma proposta para abordar assuntos sobre essa temática envolvendo o uso das TIC em uma atividade investigativa experimental.

\section{Fundamentação Teórica}

Muitos trabalhos em Ensino de Ciências utilizam-se do ensino por investigação como abordagem para orientar a elaboração de atividades e sequências didáticas (SOUZA JÚNIOR; COELHO, 2013; CARDOSO; VIANNA; CARDOSO, 2016; PORTELA, 2019; CONCEIÇÃO; OLIVEIRA; FIREMAN, 2020). Sá, Lima e Aguiar Júnior (2011) afirmam que é crescente o interesse de pesquisadores e educadores da área pelo tema. Ainda que, para eles, o termo seja polissêmico na literatura, é possível identificar alguns consensos, dentre os quais, que

a atividade investigativa é uma estratégia de ensino, entre outras, que o professor pode utilizar para diversificar sua prática no cotidiano escolar. Essa estratégia pode englobar quaisquer atividades (experimentais ou não), desde que elas sejam centradas no aluno, propiciando o desenvolvimento de sua autonomia e de sua capacidade de tomar decisões, avaliar e resolver problemas, ao se apropriar de conceitos e teorias das ciências da natureza (SÁ; LIMA; AGUIAR JÚNIOR, 2011, p. 99).

Ainda que uma única atividade investigativa possa não abranger simultaneamente todos os elementos envolvidos no ensino por investigação, Sá, Lima e Aguiar Júnior (2011) apontam algumas de suas características no ambiente escolar: proposição de um problema; aplicação e avaliação de teorias científicas; levantamento e avaliação de evidências; valorização do debate e da argumentação; presença de múltiplas interpretações. Esses e outros aspectos, como alguns dos apresentados por Azevedo (2004), foram considerados na elaboração da atividade investigativa descrita neste texto. 
Segundo Azevedo (2004), ao participarem de uma atividade investigativa, os estudantes devem não somente observar fenômenos e manipular informações ou experimentos, mas também formular hipóteses, refletir e discutir em grupo, coletar dados, explicar os argumentos utilizados e relatar suas conclusões para a resolução do problema, ou seja, participar de processos que envolvem procedimentos análogos aos científicos. Assim, considerando as aproximações e os distanciamentos entre a construção do conhecimento científico escolar e a produção de ciência pelos cientistas, os alunos podem aprender também algumas noções sobre natureza da ciência por intermédio do ensino por investigação.

Em uma atividade investigativa, é proposto inicialmente um problema aberto ${ }^{1}$, ou seja, uma pergunta é colocada de forma ampla e o mais próximo possível do cotidiano dos alunos, a fim de que eles possam atribuir sentido ao que se pretende investigar. Os estudantes, então, começam a elaborar hipóteses para tentar resolvê-lo. A partir desse momento, com base nas hipóteses e para testá-las, o professor

[...] pode sugerir, dependendo da atividade, a realização de um experimento, a análise de dados ou informações disponibilizados, a leitura de um texto, a exibição de um vídeo, o uso de uma simulação computacional, entre outras estratégias. Os estudantes se organizam em grupos e realizam alguma dessas atividades. Cada grupo analisa as informações coletadas, discute internamente, elabora uma resposta ao problema e a apresenta para toda a turma. Por fim, os grupos debatem entre si, a fim de encontrarem coletivamente a melhor solução e os argumentos mais consistentes para justificá-la (MAXIMO-PEREIRA, 2014, p. 63).

Toda a atividade é orientada e mediada pelo professor, que estimula a participação de todos, propõe questionamentos e reflexões, aponta inconsistências, formula contra-argumentos a ideias inconsistentes e realiza a síntese da discussão em direção ao conhecimento científico escolar.

Sobre o uso das TIC no ensino de Ciências, Oliveira e Jardim (2019), ao realizarem uma revisão sistemática em revistas disponíveis no Portal de Periódicos da Coordenação de Aperfeiçoamento de Pessoal de Nível Superior (CAPES), apontam que a maioria dos trabalhos relativos a essa temática somente descreve as ferramentas ou recursos tecnológicos empregados, mas não explicita as estratégias didáticas que foram utilizadas para a inserção das TICs no ensino. Os autores comentam ainda que os artigos que o fazem se vinculam a duas possibilidades de abordagem: ao ensino tradicional ou ao ensino por investigação. 
Assim, alguns trabalhos já apresentam uma aproximação entre TIC e ensino por investigação como abordagem didática, apontando possibilidades de sua utilização com experimentos remotos (CARDOSO; TAKAHASHI; OLIVEIRA, 2015) e caracterizando interações discursivas que emergem em ambientes virtuais de aprendizagem (CAMPOS SILVA; AGUIAR JÚNIOR, 2015). Para o presente texto, o ensino por investigação foi utilizado para orientar o desenvolvimento de uma atividade experimental que envolve o uso das TIC para a modelagem dos fenômenos em estudo, o estabelecimento de relações entre evidências e explicações teóricas, a discussão e comparação de resultados, entre outras características dessa abordagem didática. Passamos agora a descrever o experimento com uso das TIC que deu ensejo à elaboração da atividade investigativa a ser apresentada neste artigo.

\section{Experimento para construção de um modelo para a marcha humana}

Neto e Souza (2018) propuseram uma atividade experimental para o Ensino Médio cujo objetivo é construir um modelo matemático que relacione a velocidade de um ser humano que caminha ou corre e o comprimento de seu passo ${ }^{2}$.

Tal atividade consiste em filmar uma pessoa em duas situações distintas: enquanto caminha um dado trecho em linha reta e enquanto corre o mesmo trecho. Os pontos inicial e final do trecho podem ser delimitados por cones ou outros objetos que permitam fácil visualização na filmagem. A gravação do vídeo pode ser feita valendo-se da câmera presente nos smartphones de uso comum nos dias de hoje. Para evitar a influência da paralaxe, sugere-se que todos os dados sejam adquiridos em situações em que os alunos percorram distâncias não maiores que seis metros. Depois de gravados, os vídeos são analisados usando-se o software Tracker, por meio do qual é possível estimar os comprimentos dos passos e a velocidade da pessoa.

O Tracker é um software livre utilizado para vídeo-análise. Ele possibilita rastrear um objeto em movimento em um vídeo e extrair informações como a posição e a velocidade do mesmo em relação a uma posição de referência (KINCHIN, 2012; BEZERRA et al, 2012; PARREIRA, 2018).

Após carregar o vídeo dentro do Tracker (clicando em Arquivo -> Abrir), é necessário fixar, usando a ferramenta Bastão de Medição, a distância total percorrida, que é delimitada pelos cones (na Figura 1, linha azul entre os cones). Para tanto, 
deve-se clicar em Trajetórias -> Novo -> Ferramentas de Calibração. Após usar este comando, é preciso informar a distância total que foi percorrida. Esse valor precisa ser conhecido previamente ou ter sido medido diretamente.

Figura 1: Tela do software Tracker, utilizado no procedimento de vídeo-análise que possibilita a aquisição dos dados.

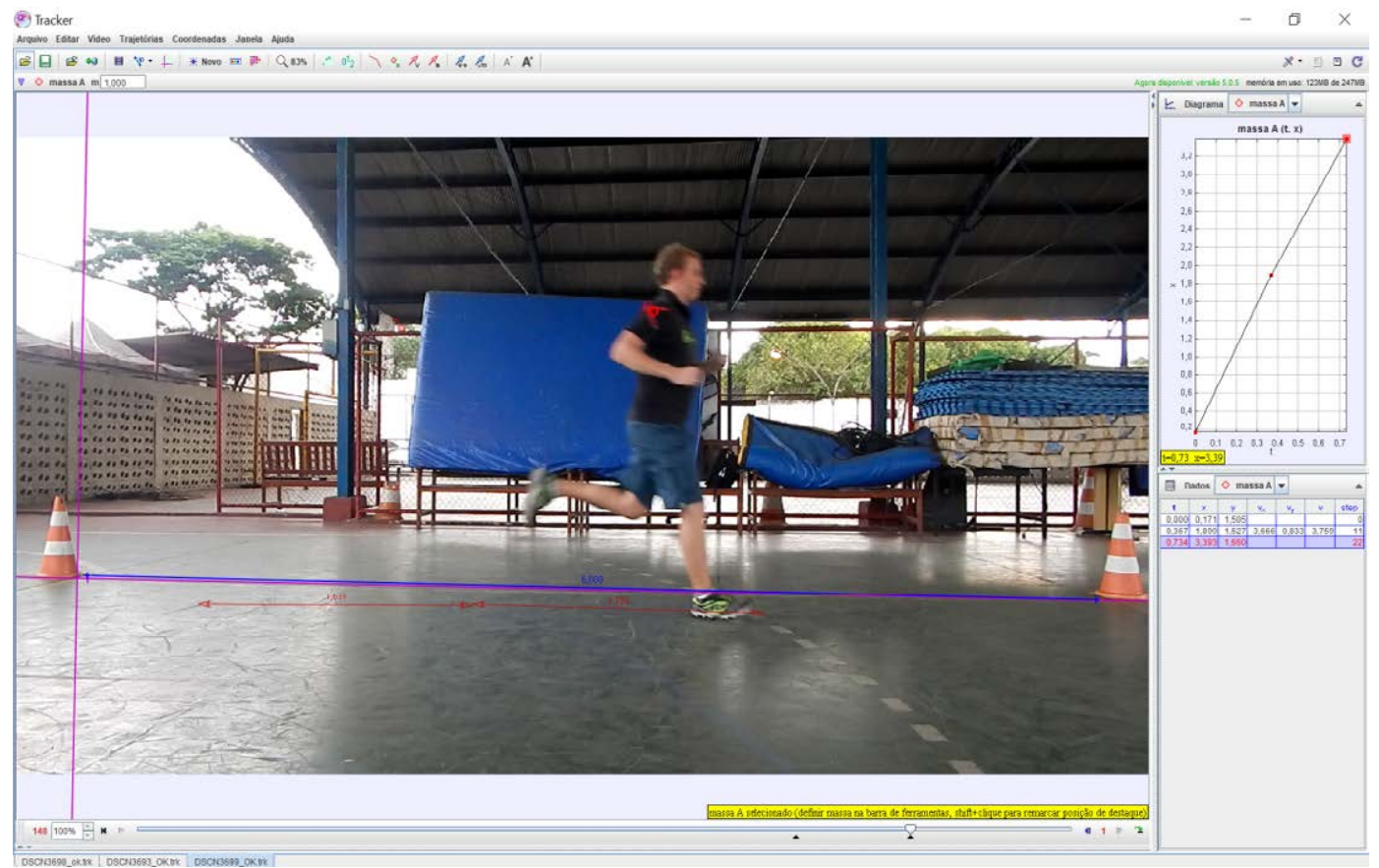

Em seguida, faz-se a medida do comprimento de cada passo utilizando-se a ferramenta Fita Métrica (clicando em Trajetórias -> Novo -> Ferramentas de Medição). As marcações para isso podem ser ajustadas quadro a quadro, demarcando o comprimento de cada passo (dois deles estão indicados em vermelho na Figura 1). Ao realizar a demarcação, o valor do comprimento aparecerá automaticamente em cima do objeto.

A estimativa da velocidade média desenvolvida durante cada passo é realizada do seguinte modo: define-se um Ponto de Massa (clicando em Trajetórias -> Novo) sobre algum ponto específico da pessoa que está correndo. Neto e Souza (2018) sugerem que um $\mathrm{X}$ de fita crepe colorida no ombro dos alunos seja usado como referência para a fixação do ponto de massa, porque é mais fácil acompanhar a trajetória dessa 
forma. Deve-se adicionar uma marcação para cada instante da pisada, que marcará o fim de um passo e o início do próximo. Para inserir a marcação, deve-se manter pressionada a tecla SHIFT e selecionar um ponto fixo do móvel (nesse exemplo, a marca no ombro da pessoa que se desloca). Ao realizar as marcações em cada ponto, uma tabela será construída automaticamente, à direita da tela, com os instantes de cada pisada (Figura 1, à direita, abaixo). Essa tabela conterá, portanto, as posições ocupadas pelo ponto de massa e os respectivos instantes de tempo.

Quando os alunos percorrem seis metros, como sugerido acima, entre dois e quatro passos são dados por cada um deles. Em aplicações dessa atividade (NETO; SOUZA, 2018), como os grupos eram compostos por quatro alunos que filmaram uns aos outros em duas situações distintas (andando e correndo), foram obtidos, ao final da atividade, oito filmes, que geraram, por sua vez, entre dezesseis e trinta e duas amostras de dados (dependendo se foram dados entre dois e quatro passos).

Os dados dos comprimentos de cada passo, assim como as posições ocupadas pelo ponto de massa e seus respectivos tempos, os quais foram obtidos com auxílio do Tracker, são inseridos em uma planilha no software LibreOffice / Calc. Com recursos da própria planilha, pode-se estimar a velocidade média com que o ponto movimentou-se naquele intervalo de tempo, o que, neste caso, coincide com a velocidade com que cada passo foi dado (basta fazer com que uma coluna seja preenchida a partir dos dados de outras duas colunas utilizando como equação a própria definição de velocidade média).

Em seguida, um gráfico de dispersão entre o tamanho de cada passo e velocidade pode ser gerado selecionando-se as colunas com os dados desejados e escolhendo a opção Inserir -> Gráfico. A modelagem matemática dos dados experimentais consiste na procura da função matemática que mais adequadamente descreve os resultados experimentais encontrados. O gráfico pode ser ajustado usando-se a ferramenta linha de tendência presente no software LibreOffice/Calc. Embora o programa apresente diversos tipos de ajuste possíveis, sugere-se que, inicialmente, para fins didáticos, se use o ajuste linear. Trata-se da função mais simples e do ajuste que mais facilmente poderia ser realizado manualmente. A equação da reta da linha de tendência é exibida quando esta opção é escolhida. É possível também avaliar a qualidade do ajuste obtido por meio da estimativa do coeficiente de determinação do ajuste, que é conseguido utilizando-se essa opção no LibreOffice / Calc. O coeficiente de determinação representa o ajustamento de um modelo estatístico aos valores 
observados, ou seja, quão bem a curva se ajusta aos dados. Uma breve discussão do significado prático desse coeficiente pode mostrar-se pertinente, tal como feito por Ayres Júnior (2018).

$\mathrm{Na}$ Figura 2, apresentamos um exemplo de um gráfico da velocidade versus comprimento dos passos, elaborado segundo o procedimento descrito anteriormente, e que considera dados de um grupo formado por quatro alunos que filmaram uns aos outros andando e correndo (oito vídeos que fornecem dezessete amostras). O ajuste apresenta excelente qualidade (coeficiente de determinação igual a 0,978). Notavelmente, o coeficiente angular da equação de ajuste $(2,49 \mathrm{~Hz})$ corresponde à frequência com que os passos são dados.

Figura 2: Gráfico da velocidade $X$ tamanho do passo para um grupo de quatro alunos filmando uns aos outros (andando e correndo). A função de ajuste e o coeficiente de determinação também são mostrados no gráfico.

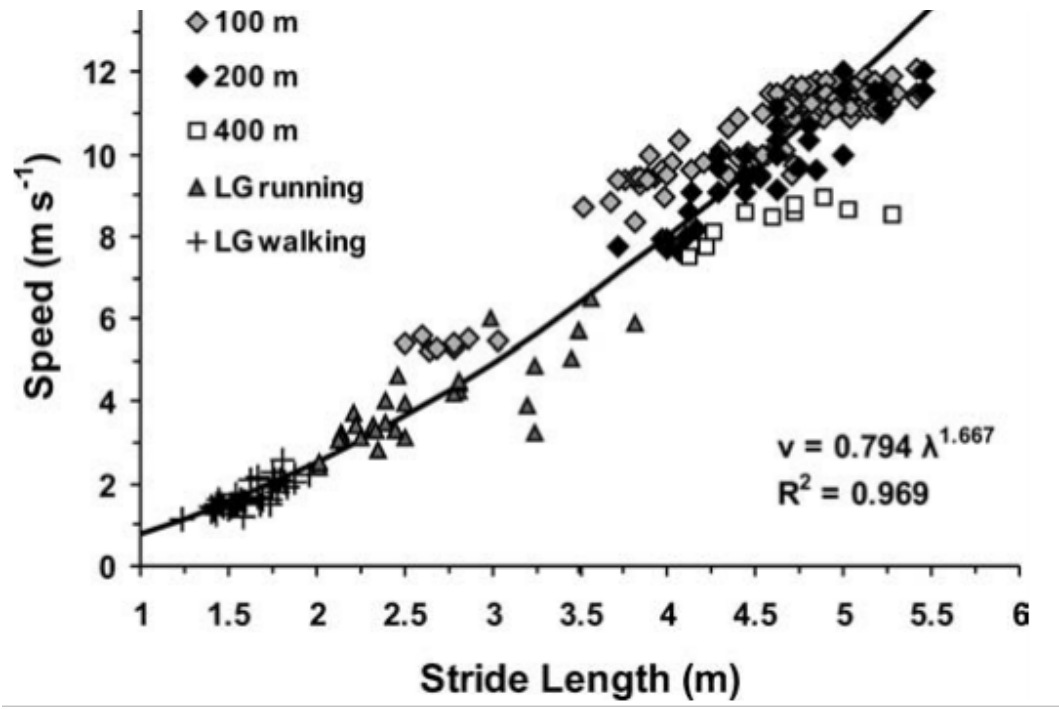

Entendemos que os resultados obtidos pelos alunos com base no experimento e nos procedimentos de análise descritos nesta seção devem ser sempre problematizados junto aos estudantes. Propomos, inclusive, que tais resultados e os modelos desenvolvidos com os ajustes possam ser comparados e/ou contrastados com outros previamente existentes literatura. 
Registros de pegadas têm sido recorrentemente utilizados na estimativa da velocidade de humanos e animais no campo da paleontologia (ALEXANDER, 1976; ALEXANDER, 1991; WEEMS, 2006; WEBB, 2007; RUIZ; TORICES, 2013). Como pode ser realizado esse processo?

Em 1976, R. Mc. Alexander propôs que o número de Froude, um parâmetro adimensional costumeiramente usado em engenharia naval, poderia ser também utilizado para analisar a velocidade de deslocamento de homens e animais. Com este objetivo, definiu o número de Froude como $V^{2} / g h$, em que $\mathrm{V}$ é a velocidade, g é a aceleração da gravidade na superfície da Terra, e h é o tamanho total dos membros posteriores, medidos do solo ao acetábulo (articulação pélvica do fêmur). Isso sugere que o tamanho da passada do animal influencia diretamente sua velocidade, o que permite que se estime a velocidade a partir do comprimento de passadas tiradas de registros fósseis.

A partir de dados experimentais, o modelo de Alexander relaciona o comprimento da passada relativa (adimensional) $\lambda / h$, em que $\lambda$ é o comprimento absoluto da passada, ao número de Froude. Matematicamente, isso consiste em afirmar que $\lambda / h \approx 2.3\left[V^{2} /(g h)^{0.3}\right]$. Segue da equação anterior que $V=0.226 g^{0,5} \lambda^{1,67} h^{-1,17}$. Segundo Alexander, essa equação pode inclusive aplicar-se tanto a dinossauros quanto a mamíferos, o que inclui os seres humanos, porque ambos os grupos de vertebrados têm seus membros embaixo do corpo.

Mais recentemente, Ruiz e Torices (2013) propuseram um modelo matemático mais simples do que o de Alexander. Eles ajustaram os dados experimentais obtidos a partir das pegadas de diversos homens e mulheres andando e correndo na areia da praia por distâncias de 100, 200 e 400 metros para modelar a relação exclusiva entre a velocidade e o comprimento da passada (RUIZ; TORICES, 2013). Na Figura 3 reproduzimos um gráfico da relação obtida experimentalmente entre a velocidade e o comprimento da passada para a amostra de Ruiz e Torices. O gráfico foi originalmente apresentado na referência (RUIZ; TORICES, 2013). 
Figura 3: Dados experimentais e curva de ajuste obtidos pela amostra de Ruiz e Torrices originalmente publicado na referência (RUIZ; TORICES, 2013).

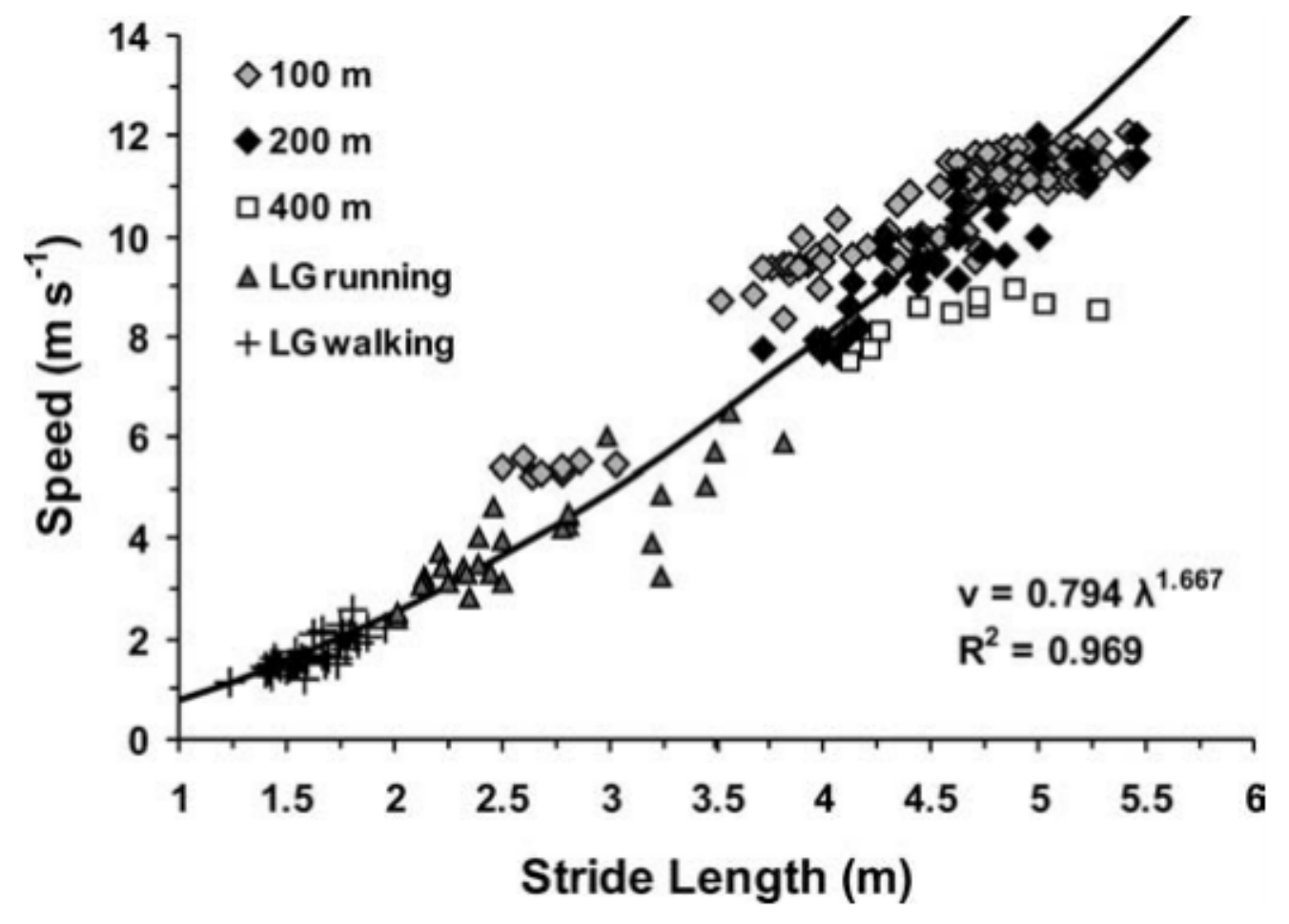

O ajuste obtido por Ruiz e Torrices (2013), $V=0,794 \lambda^{1,67}$, apresenta excelente ajuste aos dados experimentais $\left(R^{2}=0,969\right)$ e está muito próximo do modelo de Alexander para o caso em que $h \approx 1,0 m$, ou seja, para humano exclusivamente. A possibilidade de comparar os dados e ajustes obtidos pelos alunos com aqueles presentes na própria literatura justifica porque propomos que dados obtidos pelos alunos caminhando e correndo sejam ajustados juntos ${ }^{3}$.

O uso dos trabalhos de Alexander e, posteriormente, de Ruiz e Torrices (2013), para explorar outras dimensões trazidas por nós ao experimento proposto por Neto e Souza (2018) nos parece extremamente interessante porque as possíveis divergências entre os ajustes obtidos pelos estudantes e os presentes na literatura possibilitam que se possa realizar também uma discussão acerca da não existência de modelos verdadeiros ou falsos, apenas adequados ou não (FERRACIOLI, 2012; HEIDEMANN et al, 2012; HEIDEMANN et al, 2016a, HEIDEMANN et al, 2016b). A explicitação de tal visão sobre o fazer científico é um dos objetivos do ensino de ciências alinhado com o ensino por 
investigação. Com vistas a articular esse e outros aspectos dessa abordagem didática ao uso das TIC, apresentamos, na próxima seção, nossa proposta de atividade investigativa.

\section{Proposta de Atividade Investigativa: Seguindo as pegadas de Sherlock Holmes}

A fim de ampliar as possibilidades de contextualização, problematização e reflexão desencadeadas pelo experimento anteriormente descrito, elaboramos uma atividade investigativa na qual o professor inicia a aula apresentando aos alunos a seguinte proposta de atividade, que pode ser entregue em papel a cada estudante, para leitura, ou projetada para leitura por toda a turma:

Leia o trecho a seguir, extraído do livro "Um estudo em vermelho" (DOYLE, 2015):

Esse foi o primeiro ponto ganho. Caminhei, então, vagarosamente pela trilha do jardim, que era de solo argiloso, muito bom para guardar impressões. Sem dúvida aquilo pareceu a você apenas um lamaçal pisoteado, mas para meus olhos treinados cada marca tinha um significado. Não há ramo da ciência da investigação que seja tão importante e tão negligenciado quanto a arte de identificar pegadas. Por sorte, sempre me dediquei muito a isso e a prática constante fez com que se tornasse em mim uma segunda natureza (DOYLE, 2015).

Desde sua primeira aparição, em "Um estudo em vermelho" (DOYLE, 2015), o excêntrico detetive Sherlock Holmes se destacou por sua excelência na capacidade de investigar e chegar a uma conclusão. No fragmento acima, ele explica ao personagem Watson, seu fiel escudeiro, como a análise do padrão de pegadas pôde auxiliá-lo na investigação que finalmente o conduziu à solução do crime descrito no conto.

Quando nos deparamos com uma fala como a presente no fragmento, é possível perceber que a investigação de Sherlock Holmes pode ser convertida em uma investigação científica, orientada por questões como: que informações podem ser obtidas de um padrão de pegadas? Seria possível conhecer características de um suspeito de um crime estudando como ele caminha? Como fazer isso?

Diante desta problemática geral, o objetivo desta atividade é responder à seguinte pergunta: como determinar a velocidade de uma pessoa enquanto ela caminha ou corre?

Após a apresentação do problema, o professor pede que os estudantes levantem hipóteses sobre como resolvê-lo e registra no quadro as diferentes possibilidades de solução apresentadas. Dentre muitas outras, podem aparecer hipóteses como: (1) 
medir com uma régua ou trena a distância de alguns passos de uma pessoa; medir com o cronômetro o tempo necessário à realização dos passos; fazer a razão entre a distância total e o intervalo de tempo para determinar a velocidade; (2) filmar uma pessoa caminhando; medir com uma régua ou trena a distância de alguns passos dessa pessoa; verificar, pela filmagem, o tempo necessário para os respectivos passos; fazer a razão entre a distância total e o intervalo de tempo para determinar a velocidade.

O professor pode confrontar diferentes hipóteses dos estudantes, questionar procedimentos que considera inconsistentes, indicar imprecisões e incertezas associadas às propostas de medidas feitas, sugerir modos de melhorar as medições e apontar características que possam levar os alunos a escolherem uma ou outra proposta como mais adequada, entre outras considerações, a depender das hipóteses dos alunos. Como há muitas formas possíveis de solução ao problema, para orientar o planejamento do experimento e apresentar uma nova técnica de análise de dados experimentais, mais precisa e, em geral, desconhecida para os estudantes, o professor sugere o uso dos seguintes materiais: câmera de smartphone e os softwares livres Tracker e LibreOffice / Calc.

O docente, então, explica os objetivos de utilização, a forma de manipulação e as principais funcionalidades de cada um dos softwares livres separadamente. É muito importante que os exemplos de utilização Tracker e do LibreOffice / Calc ajudem os estudantes a elaborarem seus planos de trabalho para a realização do experimento, mas que sejam dados em situações completamente diferentes da que aparece no problema proposto. Esse procedimento é essencial para se manter coerência com a perspectiva do ensino por investigação, ou seja, para que os alunos não sejam apenas executores e reprodutores de procedimentos.

O objetivo pedagógico deste momento da atividade é que eles possam, ao conhecer as funcionalidades dos softwares, ter a oportunidade de identificar possibilidades de sua utilização para resolver o problema, desenvolvendo formas originais de combinação desses dois softwares. Por exemplo, o uso do Tracker pode ser exemplificado para os alunos com o estudo do movimento de um objeto lançado obliquamente (DIAS; VIANNA; CARVALHO, 2017), com a filmagem previamente feita. A elaboração de gráficos e o uso da regressão linear com o LibreOffice / Calc podem aparecer no contexto de um exemplo de outra parte da Física ou mesmo de outra disciplina escolar. 
Também é possível que esse momento da atividade (reconhecimento das formas de uso e objetivos dos softwares livres Tracker e LibreOffice / Calc) ocorra em aula anterior à atividade investigativa, igualmente com exemplos de caráter geral e diferentes daquilo que será solicitado aos estudantes na atividade investigativa proposta. Essa opção pode colocar o uso desses softwares livres como algo que poderá permear a prática do professor e que será utilizado não somente nesta atividade investigativa, mas também em outras propostas didáticas que o professor venha a fazer ao longo das aulas. Caso os softwares sejam apresentados em momento anterior, é possível que, em suas hipóteses, os alunos já apresentem o uso da filmagem e dos softwares como possibilidade de análise de dados do experimento.

Após a apresentação dos softwares (ou diretamente depois da discussão das hipóteses, caso os softwares já tenham sido apresentados previamente), o professor solicita que os alunos se reúnam em pequenos grupos e que cada grupo desenvolva uma forma de realizar o experimento e analisar seus dados que inclua o uso dos materiais fornecidos. É importante disponibilizar esse tempo para a elaboração do plano de trabalho pelos estudantes. O professor acompanha a discussão dos grupos, circula entre eles, escuta as possibilidades apresentadas, aponta possíveis incoerências e confirma bons procedimentos, faz questionamentos, esclarece dúvidas dos alunos, entre outras muitas formas de intervenção que fomentem a discussão em direção a um pensamento científico e crítico, mas que não direcionem completamente para uma única solução ao problema.

Na sequência, cada grupo apresenta, para toda a turma, a sua proposta de plano de trabalho. Em geral, é comum que apareçam proposta parecidas. O professor vai apontando aspectos relevantes, explicitando incongruências e questionando sobre como resolvê-las até que todos os grupos tenham acordo em uma proposta de plano de trabalho que leve à solução do problema proposto. É possível também que haja mais de uma proposta viável para a solução do problema, o que é um bom exemplo de que a ciência não possui uma forma única para investigar a natureza ou se chegar a um dado conhecimento. O professor pode destacar esses aspectos na discussão com os estudantes.

É relevante mencionar que não necessariamente os grupos chegarão a uma forma de realização do experimento e análise de dados idêntica à proposta de Neto e Souza (2018), apresentada anteriormente neste texto. A proposição dos autores deve ser apenas um guia de referência para que o professor faça suas intervenções 
no sentido de construir com os alunos uma maneira viável e mais precisa para realizar o experimento e a análise de dados.

Os grupos, então, executam o plano de trabalho, analisam as imagens e determinam a velocidade do passo das pessoas e situações previamente escolhidas, sempre com a supervisão do professor. Cada grupo apresenta para toda a turma sua solução ao problema e seus resultados para as velocidades em cada situação escolhida (corrida, caminhada, com meninos, com meninas, etc.).

Nesse ponto, o professor pode chamar a atenção para os diferentes valores de velocidade obtidos e propor um novo problema para os estudantes: os valores de velocidade do passo obtidos são aleatórios ou existe algum padrão de comportamento para essas diferentes velocidades, em diferentes contextos (corrida e caminhada) e para diferentes pessoas? Caso não sejam aleatórios, de que depende a velocidade do passo e como determinar esse padrão de comportamento?

Após a proposta do novo problema, os alunos levantam suas hipóteses para respondê-lo. Alguns podem achar que os valores de velocidade do passo são aleatórios; outros podem dizer que isso depende da pessoa que anda ou corre (se é alta ou baixa, gorda ou magra, tem a perna grande ou pequena). A menção ao tamanho da perna pode ser uma forma de o professor introduzir a possibilidade de se associar a velocidade do passo ao tamanho do mesmo, caso ela não seja apontada pelos alunos. Assim, para investigar essa possibilidade, o docente pode sugerir aos grupos o uso do LibreOffice / Calc para a elaboração do gráfico de velocidade do passo em função de seu comprimento, nos moldes daquele da Figura 2, considerando os dados de toda a turma.

O professor solicita, então, que os alunos analisem o padrão de dispersão dos dados no gráfico obtido, observando se há algum tipo de relação entre a variável dependente (velocidade do passo) e a independente (tamanho do passo). Pode ser sugerida uma primeira aproximação linear para descrever esse comportamento de modo mais simplificado, utilizando os recursos do LibreOffice / Calc, para se obter uma relação possível entre as duas variáveis e a resposta ao problema proposto.

Cada grupo apresenta sua proposta de solução, descrevendo os procedimentos desenvolvidos para isso. Dependendo de como foi o andamento da discussão entre os grupos, das intervenções dos alunos, dos objetivos do professor com a atividade, do conhecimento matemático dos estudantes e do nível de apropriação no uso do Tracker e do LibreOffice/Calc, o professor pode aprofundar mais ou menos a 
questão da regressão linear, do coeficiente angular da reta obtida, da incerteza nas medições, entre outros aspectos que permeiam a atividade e/ou que podem ser aventados pelos estudantes.

O professor pode ainda apresentar os estudos já citados anteriormente (ALEXANDER, 1976; RUIZ; TORRICES, 2013) e discutir em que medida tais trabalhos são comparáveis à atividade realizada pelos próprios alunos. O professor pode fazê-lo retomando todas as etapas da atividade desenvolvidas até então e salientando aos alunos que a ciência que se aprende na escola pode ser ensinada de forma a apresentar a eles algumas práticas que se aproximam daquelas que caracterizam o trabalho dos cientistas, como é o caso da atividade da qual eles estão participando.

Seguindo nessa dinâmica, o docente pode propor que os resultados obtidos pelos grupos e pela literatura sejam comparados, o que permite que se discuta o que são modelos, de que forma e em que medida descrevem o fenômeno observado, quais são suas limitações e porque são (ou não) confiáveis. O processo de modelagem envolve desde a familiarização com um problema a ser investigado até a obtenção de uma função matemática, a comparação com outros resultados previamente existentes e as divergências entre as previsões obtidas entre os grupos de alunos e deles com a literatura.

Esse último aspecto pode ser explicitado pelo professor como sendo característico de uma concepção de ciência que concebe a não existência de uma verdade única e absoluta, já que o mesmo experimento, realizado em condições diferentes ou mesmo similares, pode gerar distintos valores para os coeficientes de uma formulação matemática. Tal fato mostra que não existem modelos verdadeiros ou falsos, apenas adequados, justamente porque descrevem bem os dados experimentais e têm boa concordância com modelos similares já disponíveis na literatura relativa a um dado conhecimento (VIANNA; CARVALHO, 2000; CARVALHO, 2005).

\section{Considerações finais}

O objetivo deste artigo foi apresentar uma proposta de atividade investigativa experimental que envolve o uso das TIC na elaboração de um modelo para o caminhar de uma pessoa. O problema de investigação foi proposto em um contexto de suspense e mistério, cujo pano de fundo é um fragmento do livro "Um estudo em vermelho" (DOYLE, 2015), no qual a personagem Sherlock Holmes fez sua primeira 
aparição. A presença da literatura, associada à proposição do problema da atividade investigativa, e das TIC, na elaboração da solução ao problema, são características que podem contribuir para que os estudantes atribuam novos sentidos ao conhecimento e às práticas científicas.

Para a solução ao problema, foram disponibilizados os softwares livres Tracker e LibreOffice / Calc, ambos disponíveis para o ambiente Linux, que, por sua vez, também é livre. A utilização de softwares livres visa a permitir que a atividade proposta neste texto possa ser facilmente aplicada nos mais diversos contextos escolares e se alinha à ideia de que uma educação de qualidade é um direito universal, que não pode ser de qualquer modo cerceado nem restrito apenas aos alunos e às instituições escolares que possam pagar por softwares.

As etapas de proposição do problema aberto, levantamento de hipóteses, desenvolvimento do procedimento experimental, coleta e análise de dados, apresentação e problematização dos resultados e de resposta ao problema, características de uma atividade investigativa, foram apresentadas para a atividade proposta neste texto. Com a mediação do professor, tanto na explicação sobre o uso dos softwares como na discussão sobre como realizar o experimento, analisar os dados e avaliar resultados, os grupos de alunos têm a possibilidade de construir modelos que descrevem os dados coletados, participando, no contexto escolar, de atividades que se assemelham às que são realizadas por cientistas.

Propusemos ainda a comparação dos resultados experimentais obtidos com outros presentes na literatura como possibilidade de se discutir explicitamente com os alunos características do fazer científico subjacentes a uma visão mais ampla de ciência, entendida como construção humana em permanente transformação, passível de alterações, melhorias, novas aproximações e formulações. Incluímos sugestões de como o professor pode proceder para atuar nesses momentos em sala de aula. Consideramos ser possível que os docentes possam adaptar as etapas da atividade investigativa e/ou as discussões apontadas neste texto a seus contextos de trabalho e à realidade escolar na qual se inserem. Por exemplo, a atividade aqui apresentada pode ser simplificada em termos matemáticos, sem a abordagem de análise de gráficos, ajuste de curvas, etc., para ser utilizada no $9^{\circ}$ ano do Ensino Fundamental, momento da escolarização em que, por vezes, a Cinemática também é abordada. Nesse caso, a ênfase de Seguindo as pegadas de Sherlock Holmes seria na experimentação de caráter investigativo, no confronto entre diferentes resulta- 
dos, na proposição de modelos provisórios, em suma, na iniciação dos estudantes às práticas e ao pensamento científicos que explicitam uma visão de ciência como algo em permanente construção.

A proposta apresentada neste texto contempla o ensino de assuntos de Cinemática de forma bastante diferente das usualmente utilizadas na Educação Básica. Ela aponta para a potencialidade de se associar as TIC ao ensino por investigação, a fim de superar o argumento de que o uso dessas tecnologias se justifica por si mesmo, de forma "intuitiva", apenas porque elas estão presentes no contexto do atual estágio de desenvolvimento no qual a sociedade se encontra ou porque elas parecem motivar os alunos. Procuramos mostrar que as TIC podem fornecer uma importante contribuição à aprendizagem de conhecimentos e de práticas que caracterizam o fazer científico, desde que sejam utilizadas no contexto de atividades elaboradas para tais finalidades, sendo o ensino por investigação uma abordagem didática apropriada para isso.

\section{Following the footsteps of Sherlock Holmes: a proposal of inquiry-based activity using new technologies}

\section{Abstract}

Rethinking the role of new information and communication technologies (ICT) in teaching and reflecting on the approach to teach Kinematics in High School are two important subjects of the research on Physics Teaching. This work presents an experimental inquiry-based activity that involves the use of ICT in the development of a model the human gait. The question that gives rise to the activity is based on a fragment of the book "A Study in Scarlet", in which the famous character Sherlock Holmes made his debut in literature. The experiment data are obtained and treated using the free softwares Tracker and LibreOffice/Calc. This article shows that ICT can provide an important contribution to the learning of knowledge and practices that characterize the scientific making, as long as they are used in the context of activities designed for such purposes. The inquiry-based teaching seems to be an appropriate didactic approach for this.

Keywords: Physics Teaching; Inquiry-based teaching; ICT; Kinematics.

\section{Notas}

1 De acordo com Jiménez-Aleixandre et al. (2003, p. 249), um problema aberto "[...] nem sempre significa uma variedade de soluções, mas ter que decidir (e justificar) cada passo dado para resolver o problema".

2 Neste contexto, passo é definido como a distância entre duas pegadas sucessivas com pés diferentes, enquanto passada consiste na distância entre duas pegadas sucessivas com o mesmo pé. 
3 Nada impede, todavia, que esses conjuntos de dados sejam ajustados separadamente em outro momento, o que certamente gerará uma interessante discussão em torno das diferenças entre andar e correr do ponto de vista biomecânico.

\section{Referências}

ALEXANDER, Robert McNeill. Estimates of speeds of dinosaurs. Nature, v. 261, n. 5556, p. 129-130, 1976.

ALEXANDER, Robert McNeill. How dinosaurs ran. Scientific American, 261, p. 130-136, 1991.

AYRES JÚNIOR, Ronaldo Fernandes. Força centrípeta: um experimento de baixo custo para o ensino médio. IF-UFRJ(Rio de Janeiro), 2018. Dissertação de mestrado, Universidade Federal do Rio de Janeiro, 2018.

AZEVEDO, Maria Cristina Paternostro Stella. Ensino por investigação: problematizando as atividades em sala de aula. In: CARVALHO, Anna Maria Pessoa de . Ensino de ciências: unindo a pesquisa e a prática. São Paulo: Pioneira Thomson Learning, 2004.

BARROS, Suzana de Souza. Reflexões sobre 30 anos de pesquisa em ensino de Física. In: VIII Encontro Nacional de Pesquisa em Ensino de Física, Águas de Lindóia. Anais... Águas de Lindóia, 2002.

BELMONT, Rachel Saraiva; MAXIMO-PEREIRA, Marta; LEMOS, Evelyse dos Santos. Integrando Física e Educação Física em uma atividade investigativa na perspectiva da teoria da aprendizagem significativa. Experiências em Ensino de Ciências, 11, p. 124-135, 2016.

BEZERRA JÚNIOR, Arandi Ginane et al. Videoanálise com o software livre Tracker no laboratório didático de Física: movimento parabólico e segunda lei de Newton. Caderno Brasileiro de Ensino de Física, v. 29, p. 469-490, 2012.

BUSE, Andrei. Um olhar diferenciado sobre a cinemática no ensino médio: uma abordagem praxeológica das tarefas. UFSC (Florianópolis), 2018. Dissertação de mestrado, Programa de Pós Graduação em Educação Científica e Tecnológica da Universidade Federal de Santa Catarina, 2014.

CAMPOS SILVA, Stella Maria; AGUIAR JÚNIOR, Orlando Gomes. O papel do professor em ambiente de aprendizagem colaborativo e investigativo mediado pelo computador: uma análise das interações discursivas e multimodais. In: X Encontro Nacional em Educação em Ciências, Águas de Lindóia. Anais... Águas de Lindóia, 2015.

CARDOSO, Dayane Carvalho; TAKAHASHI, Eduardo Kojy; OLIVEIRA, T. M. Possibilidades e Limitações relacionadas ao uso de experimento remoto em uma abordagem investigativa. In: $\mathrm{X}$ Encontro Nacional de Pesquisa em Educação em Ciências, Águas de Lindóia. Anais... Águas de Lindóia, 2015.

CARDOSO, Suelen Pestana; VIANNA, Deise Miranda; CARDOSO, Simone Coutinho. Aplicações Industriais da Física das Radiações: um enfoque CTS. Latin-American Journal of Physics Education, v. 10, n. 4, p. 18, 2016.

CARVALHO, Anna Maria Pessoa de. Introduzindo os alunos no universo das ciências. In: WERTHEIN, Jorge; DA CUNHA, Célio. Educação científica e desenvolvimento: o que pensam os cientistas. Unesco, Representação no Brasil, 2005. 
CONCEIÇÃO, Alexandre Rodrigues; OLIVEIRA, Rosemeire da Silva Dantas; FIREMAN, Elton Casado. Ensino de Ciências por Investigação: Uma Estratégia Didática para Auxiliar a Prática dos Professores dos Anos Iniciais do Ensino Fundamental. Revista Brasileira de Ensino de Ciências e Matemática, v. 3, n. 1, 2020.

DE JESUS, Vitor Luiz Bastos; SASAKI, Daniel Guilherme Gomes. Vídeo-análise de um experimento de baixo custo sobre atrito cinético e atrito de rolamento. Revista Brasileira de Ensino de Física, v. 36, n. 3, p. 1-6, 2014.

DE JESUS, Vitor Luiz Bastos; SASAKI, Daniel Guilherme Gomes. Uma abordagem por videoanálise da propagação de um pulso em uma catenária. Revista Brasileira de Ensino de Física, v. 38 , n. $3,2016$.

DIAS, Marco Adriano; VIANNA, Deise Miranda; CARVALHO, Paulo Simeão Contribuições de imagens estroboscópicas e da vídeo-análise para intervenções didáticas de investigação. In: XXII Simpósio Nacional de Ensino de Física, São Paulo. Atas... São Paulo, 2018.

DOYLE, Arthur Conan. Um estudo em vermelho. São Paulo: Editora Pandorga, 2020.

FERRACIOLI, Laercio et al. Ambientes de modelagem computacional no aprendizado exploratório de física. Caderno Brasileiro de Ensino de Física, v. 29, p. 679-707, 2012.

FOUREZ, Gérard. Crise no ensino de ciências? Investigações em ensino de ciências, v. 8, n. 2, p. 109-123, 2016.

FRAIHA, Simone et al. Atividades investigativas e o desenvolvimento de habilidades e competências: um relato de experiência no curso de Física da Universidade Federal do Pará. Revista Brasileira de Ensino de Física, v. 40, n. 4, 2018.

GASPAR, Alberto. $O$ " $R$ " de retilíneo. Caderno Brasileiro de Ensino de Física, 11, 1, p. 7-10, 1994.

HEIDEMANN, Leonardo Albuquerque; ARAUJO, Ives Solano; VEIT, Eliane Angela. Ciclos de modelagem: uma proposta para integrar atividades baseadas em simulações computacionais e atividades experimentais no ensino de física. Caderno brasileiro de ensino de física. v. 29, n. 2, p. 965-1007, 2012.

HEIDEMANN, Leonardo Albuquerque; ARAUJO, Ives Solano; VEIT, Eliane Angela. Modelagem Didático-científica: integrando atividades experimentais e o processo de modelagem científica no ensino de Física. Caderno Brasileiro de Ensino de Física, v. 33, n. 1, p. 3-32, 2016.

HEIDEMANN, Leonardo Albuquerque; ARAUJO, Ives Solano; VEIT, Eliane Angela. Atividades experimentais com enfoque no processo de modelagem científica: uma alternativa para a ressignificação das aulas de laboratório em cursos de graduação em física. Revista Brasileira de Ensino de Física. v. 38, n. 1, p. 1504, 2016.

JIMÉNEZ ALEIXANDRE, María Pilar et al. Enseñar ciencias. Serie Didáctica de las ciencias experimentales. Santiago: Editorial Graó (2003). 2003.

KINCHIN, John. Tracker demonstrates circular motion. Physics Education, v. 47, n. 1, p. 15, 2012.

LIMA, Magali Fonseca de Castro; SOARES, Vitorvani. Brincar para construir o conhecimento: jogo e cinemática. A Física na Escola, v. 11, p. 24-26, 2010. 
MAXIMO-PEREIRA, Marta. Memória mediada na aprendizagem de Física: problematizando a afirmação "Não me lembro de nada das aulas do ano passado!". 2014. Tese (Doutorado em Ensino de Física) - Ensino de Ciências (Física, Química e Biologia), Universidade de São Paulo, São Paulo, 2014.

MENEZES, Luiz Carlos de. Tempo de avaliação. In: X Simpósio Nacional de Ensino de Física, Londrina. Atas... Londrina, 1993.

MOREIRA, Marco Antonio. Uma análise crítica do ensino de Física. Estudos avançados, v. 32, n. 94, p. 73-80, 2018.

NARDI, Roberto; DE ALMEIDA, Maria José Pereira Monteiro. Formação da área de ensino de ciências: memórias de pesquisadores no Brasil. Revista Brasileira de Pesquisa em Educação em Ciências, v. 4, n. 1, 2004.

NETO, Fernando dos Santos; SOUZA, Paulo Victor Santos. Modeling human gait in high school. Physics Education, v. 53, n. 5, p. 055022, 2018.

OLIVEIRA, Fernando Sian; JARDIM, Maria Inês de Affonseca. Metodologias para o uso de tecnologias digitais de informação e da comunicação no ensino de ciências: uma revisão sistemática. In: XII Encontro Nacional de Pesquisa em Ensino de Ciências, Natal. Atas... Natal, 2019.

PARREIRA, Júlia Esteves. Um curso de Mecânica com o uso do programa de vídeo-análise Tracker. Caderno Brasileiro de Ensino de Física, v. 35, n. 3, p. 980-1003, 2018.

PENA, Fábio Luís Alves. Por que, apesar do grande avanço da pesquisa acadêmica sobre ensino de Física no Brasil, ainda há pouca aplicação dos resultados em sala de aula?. Revista Brasileira de Ensino de Física, v. 26, n. 4, p. 293-295, 2004.

PIRES, Marcelo Antonio; VEIT, Eliane Angela. Tecnologias de Informação e Comunicação para ampliar e motivar o aprendizado de Física no Ensino Médio. Revista Brasileira de Ensino de Física, v. 28, n. 2, p. 241-248, 2006.

PORTELA, Caroline Dourada Pereira. Ensino por investigação: possibilidades e reflexões no PIBID Física IFPR. Curitiba: Editora IFR, 2019.

RUIZ, Javier; TORICES, Angélica. Humans running at stadiums and beaches and the accuracy of speed estimations from fossil trackways. Ichnos, v. 20, n. 1, p. 31-35, 2013.

SÁ, Eliane Ferreira; DE CASTRO LIMA, Maria Emília Caixeta; AGUIAR JR, Orlando. A construção de sentidos para o termo ensino por investigação no contexto de um curso de formação. Investigações em Ensino de Ciências, v. 16, n. 1, p. 79-102, 2016.

SASSERON, Lúcia Helena. Alfabetização Científica, Ensino por Investigação e Argumentação: relações entre ciências da natureza e escola. Ensaio Pesquisa em Educação em Ciências, v. 17, n. spe, p. 49-67, 2015.

SENRA, Clarice Parreira; BRAGA, Marco Antonio Barbosa. Pensando a natureza da ciência a partir de atividades experimentais investigativas numa escola de formação profissional. Caderno Brasileiro de Ensino de Física, v. 31, n. 1, p. 7-29, 2014.

SOLINO, Ana Paula; FERRAZ, Arthur Tadeu; SASSERON, Lúcia Helena. Ensino por investigação como abordagem didática: desenvolvimento de práticas científicas escolares. In: XXI Simpósio Nacional de Ensino de Física, Uberlândia. Atas... Uberlândia, 2015. 
SOUSA, José Mauro; DOS SANTOS MALHEIROS, Ana Paula; FIGUEIREDO, Newton. Desenvolvendo práticas investigativas no Ensino Médio: o uso de um Objeto de Aprendizagem no estudo da Força de Lorentz. Caderno Brasileiro de Ensino de Física, v. 32, n. 3, p. 988-1006, 2015.

SOUZA, Paulo Victor Santos; DONANGELO, Raul José. Velocidades média e instantânea no Ensino Médio: uma possível abordagem. Revista Brasileira de Ensino de Física, v. 34, n. 3, p. 1-6, 2012.

SOUZA JUNIOR, Domingos Rodrigues; COELHO, Geide Rosa. Ensino por investigação: problematizando as aprendizagens em uma atividade sobre condutividade elétrica. In: IX Encontro Nacional de Pesquisa em Educação em Ciências, Águas de Lindóia. Atas... Águas de Lindóia, 2013.

VIANNA, Deise Miranda; CARVALHO, Anna Maria Pessoa de. Formação permanente: a necessidade da interação entre a ciência dos cientistas e a ciência da sala de aula. Ciência \& Educação, p. 30-42, 2000.

VITAL, Abigail; GUERRA, Andreia. A natureza da ciência no ensino de Física: estratégias didáticas elaboradas por professores egressos do mestrado profissional. Caderno Brasileiro de Ensino de Física, v. 31, n. 2, p. 225-257, 2014.

WEEMS, Robert Locomotor speeds and patterns of running behavior in non-maniraptoriform theropod dinosaurs. New Mexico Museum of Natural History and Science Bulletin, v. 37, p. 379-389, 2006.

WEBB, Steve. Further research of the Willandra Lakes fossil footprint site, southeastern Australia. Journal of human evolution, v. 52, n. 6, p. 711-715, 2007. 